\title{
Pathways to Inclusion: a guide to staff development
}

\author{
BENGT PERSSON \\ Agder University College, Kristiansand, Norway
}

Pathways to Inclusion: a guide to staff development

RÓSA EGGERTSDOTTIR, GRETAR L. MARINÓSSON (EDITOR), CHARLES SIGALES, INGIBJÖRG AUðXUNSDÓTTIR, HALLDÓRA AUðXUNSDOTTIR, JOSÉ PACHECO, MARIANNE WILHELM, ðORA BJÖRK JÓNSDÓTTIR, 2005

Reykjavik: University of Iceland Press

244 pp. + CD disc, ISBN 9979546468

\section{Introduction}

The inclusion movement has its roots in the civil rights movement in the USA. It became a powerful public influence in the 1980s, resulting in a change of public policy in 1986 in connection with the Regular Education Initiative (REI). Under the generic term 'inclusion' a movement arose aiming at creating public social and educational environments in which individuals with various kinds of disabilities were to be included. This endeavour was expanded during the 1990 s principally by the Association for Persons with Severe Handicaps (TASH) by also comprising individuals with more severe disabilities.

The Scandinavian countries also have a tradition of trying to place and integrate students with disabilities in regular classes. Nils Erik Bank Mikkelsen in Denmark and Bengt Nirje in Sweden are perhaps the most prominent advocates for what has been known as the 'normalization principle'. In short, this principle stressed the obligation for society to increase accessibility to public services for all citizens.

Inclusion is an ideological project resting upon humanistic values such as equality, solidarity and man's inviolability. Such values or norms make up and shape democratic societies, pointing the direction towards which institutions and citizens should move. In the context of education, inclusion basically implies promoting heterogeneously composed groups, classes and schools, thereby counteracting organizational solutions such as ability grouping, tracking or streaming.

In the last few decades special education research has widened its focus of interest to comprise not only individuals with different kinds of disabilities, but also the educational settings to which these pupils belong. This trend features in most countries in the Western world and is more often than not connected with debates marked by strong ideological undertones. In a wider sense this debate deals with the issue of whether or not an inclusive system is preferable to one whereby the incentives provided are for segregated settings.

In the USA this debate was extremely intense during the 1990s, and research within this field was often described as being ideological and results as being politically influenced. In the late 1990s Ellen Brantlinger, researcher at the University of Indiana, made an important contribution to elucidating this clash of interests in an article published in the Review of Educational Research (Brantlinger, 1997). Brantlinger suggests that the debate for or against inclusion has become 
increasingly polarized. She calls into question the ethics involved in the practice of using research results to categorize young people due to their school-related difficulties and thereafter place them in special programmes adapted to their alleged needs:

Using the language of civil rights, advocates of inclusion describe pull-out programs as segregated and discriminatory. Those on the other side feel that inclusion does not meet the special needs of all students with disabilities. (p. 429)

She continues:

With a charitable, we-are-doing-good-for-them image, special education blesses 'patient' and 'dedicated' professionals and disguises insidious effects on powerless students by euphemisms and silences. (p. 441)

A fundamental question is thus how we define the concept of inclusion; what arguments underpin its justification. Fuchs \& Fuchs (1997) warn against an unholy alliance between advocates for inclusion and those responsible for economy in schools and school districts and claim the following:

calls for full inclusion - eliminating special education placements and redeploying resources into mainstreaming settings - will be understood to mean that all children can survive on a regular education diet; that monies saved by downsizing special education can be returned to taxpayers. (p. 229)

Inclusion is thus a slippery concept - not easy to define but politically correct to use. Paradoxically, however, inclusive education in many countries seems to have become the responsibility of special educators. In the USA 'Inclusive Education Facilitators' often work in local educational systems, striving to make inclusive organization arrangements in schools. Inclusive education has led to farreaching challenges for special education as it questions the traditional role of special education teachers as 'helpers'.

Handbooks, guidelines and anthologies of different kinds have been published in recent years pointing out practicable ways to implement an inclusive schooling philosophy. In the year $2000 \mathrm{a}$ large-scale project was initiated by UNESCO with the purpose of producing a handbook for local education authorities and politicians. The service package (Schools for All: open file on inclusive education) was worked out as a joint project by researchers, practitioners and school administrators from all over the world. The handbook is based on good practice in a number of countries, and points out some critical issues related to the implementation of an inclusive practice:

Few schools would disagree with inclusion as a principle. However, many have reservations about the practice of inclusion and even those which attempt to become more inclusive may find themselves lacking adequate support. The issue for administrators and decision-makers,

therefore, is how best to work with schools in order to build on their experiments with inclusion, overcome any uncertainties they may have and enable them to develop more effective inclusive practices. (UNESCO, 2000)

The authors also point out the need for school-based approaches to involve building on initiatives taken by schools themselves. In order for these approaches to be effective, a number of conditions must be present:

1. There needs to be a national and/or local context in which innovation is permitted and, where possible, encouraged;

2. Schools need to be offered practical support for their initiatives, even where such initiatives cut across established practices and procedures at higher levels of the system;

The lessons learned by innovating schools need to be disseminated to other schools and those schools need to be offered encouragement to become more inclusive in turn. (UNESCO, 2000)

In the Nordic context a comprehensive textbook was published in 2004 covering almost all parts of the special/inclusive education field - Spesialpedagogikk - edited by two Norwegian professors, Edvard Befring \& Reidun Tangen. This book discusses fundamental perspectives and values, and is built on empirical research and a wealth of experience. 


\section{The Project: 'Pathways to Inclusion'}

The project, which is a part of a Leonardo da Vinci project called Enhancing Teachers' Ability in Inclusion (ETAI), was started in 1998 by a collaborative team of 22 researchers and teachers in Austria, Iceland, Portugal and Spain. The project was finished in 2001 and resulted in the handbook reviewed here.

In the Preface the authors describe the working process, research methods used, and the participating schools in the project. They also include a short passage where the characteristics of 'inclusive education' are outlined. In this part of the book, the authors introduce the reader to the content of the handbook. Variation among schools is considerable, and in their summary the authors describe such diversity as a challenge to the ETAI-team. However, since comparison among countries or schools was irrelevant to the project, this variation could have been left out of the account.

Part Two deals with the main outcomes from the case studies. Nine themes emerged from the studies, each of them comprising a chapter together with a concluding section in which implications for practice are drawn. The chapters deal with issues such as preparation for schooling, curriculum and individual educational plans, classroom practice, collaboration, social interaction, home-school collaboration, evaluation support services and staff development, i.e. central and important themes in inclusive practices. Each chapter is followed by relatively detailed and tangible suggestions for classroom practice. The concluding implications of the study are presented in the last chapter, where the threads are drawn together in an exemplary way. The authors conclude that what underlies successful implementation of inclusive education is 'firm beliefs in the basic human rights of education for all, independence and equality' (p. 54). Schools have to function as communities rather than as efficient service suppliers in the market. Collaboration is superior to competition, and pupils and parents are seen as being important citizens rather than customers. Inclusion is created and constructed in collaboration where staff, pupils and parents are involved and process is emphasized rather than effect. It is something worth aiming for as a natural element of democracy. No wonder the notion of inclusion is exposed to pressure from forces working in the market where competition, accountability, and self-realization are important characteristics.

Part three - Handbook for Staff Development - is the cardinal part of the book. The initial purpose of the ETAI project was 'to encourage teachers' abilities in inclusion in ordinary schools'. In order to attain this aim, staff should be encouraged to 'reflect on practice, analyse situations, solve problems, make decisions, plan for policies and actions and finally evaluate current situation' (p. 56). In the rest of the review essay I will present and discuss each chapter of this part of the book, followed by a commentary related to the stated objectives. The objectives of each chapter emanate from findings from the fieldwork study, followed by a section on the implementation of the objectives in schools.

\section{Preparation for Schooling}

In this chapter the reader is presented with a number of aspects of preparation for schooling. This comprises early collaboration between parents, school staff and experts, with teachers acting as responsible initiators and coordinators. The implementation processes are described thoroughly, and detailed recommendations are made as to how to carry out the work practically. Several detailed schemes and plans for completion are also presented.

\section{Curricula and Individual Education Plans}

The second chapter deals with a variety of issues regarding curricula and individual education plans. Class teachers' responsibilities for the drawing up of such plans as well as for designing curricula are emphasized. The importance of the focus for goals being set is discussed, and the authors especially point out how essential it is to promote social as well as educational goals. A sound reflection is that 'an individual educational plan can simultaneously encourage and restrict pupils' participation and involvement in class' (p. 76). An issue not explicitly discussed is the weight of using a communication-friendly language in the IEPs. Previous research has shown that 
sometimes not even the professionals involved understand the content of plans. Cooper (1996) writes the following:

Central issues here are the need to ensure that students and their parents are fully involved in the development of IEPs, and that the IEP is constructed in a way that is accessible to, and understood by, parents and students. It is also vitally important that the goals and objectives defined in the IEPs can be and are implemented. Underpinning everything is the need for an effective and comprehensive review and evaluation process, whereby evaluation applies not only to the outcomes (of the IEP itself), but also to the stages of its development. (p. 118)

Similar to Cooper, the authors of the ETAI-study point out the importance of involving parents and pupils in the IEP process. However, it is worth remembering the dominant position that professionals hold, especially in relation to pupils, an issue that was highlighted in a recent Swedish investigation (Swedish Agency for Education, 2003):

The interviews give a rather disappointing picture of the chances for pupils' equal participation.

Many express a kind of powerlessness which might be easily understood in the light of the

subordinate position the pupil has as his problems are being discussed by his parents and school staff. (p. 82)

Professionals need to pay attention to the fact that children - especially those with special needs may lack any understanding of how do deal with their 'problems'. Andreasson (forthcoming) refers to Foucault (1974/1993) when she discusses the oppressive but subtle power that might be exercised towards pupils in different kinds of individual plans and programmes and writes:

But by means of such normalizing practices, people's identities could be formed and they may

begin to look at themselves as a 'problem child', untalented etc. Through examination

surveillance and normalization become linked together. 'The examined' becomes visible,

substantiated and documented while the examiner keeps on being invisible.

The writing of individual education plans is preceded by pedagogical analyses and statements where the pupils' difficulties and needs are described in order to bring about adequate actions. Such processes may, at worst, result in the construction of pupils' identities that are seen as being 'deviant'. Ethical considerations are therefore of great importance in such work.

\section{Classroom Practice}

The objective of this chapter is to highlight the values of pupil diversity, communication, collaboration and interaction, curriculum adaptation and team teaching. In inclusive classrooms, differences between pupils are valued and seen as opportunities, and it is stressed that all children have special needs which must be satisfied, not only those whose needs are quite obvious.

The most challenging issue concerning the implementation of inclusive education in the classroom is obviously how to satisfy the needs of all pupils. Teachers need to find strategies and skills on how to use heterogeneity as a resource. As inclusion is about belonging to a society and being valued as one of its members, social interaction and cooperation become keywords, which in turn presuppose teachers working together in teams. The authors emphasize that such a culture needs to be present if inclusion is to become successful. A number of highly relevant activities are proposed, followed by concrete examples for practice and directions.

\section{Collaboration and Coordination}

Findings from the ETAI study show that one of the cornerstones of successful inclusive schooling is collaboration among teachers. This is apparent in all schools included in the study. The results also show that such collaboration aimed at providing and ensuring access for all pupils and sharing responsibility in order to attain common goals. Yet another interesting finding from the study is the role of specialists and experts. The quality of their work increased considerably when they worked closely with staff instead of focusing their attention on clinical work with individual pupils.

The research team emphasizes the need for different professional categories to work together in order to create a culture where access and sense of belonging are important characteristics. 
Inclusive schooling is such a complex enterprise that special knowledge and skills are needed for schools to operate.

Practical advice is provided at the end of the chapter about how to develop strategies and skills for collaboration with all kinds of professionals inside and outside the school.

\section{Pupils' Social Interaction}

Just as important as collaboration among staff is pupils' social interaction. Results from the ETAI study make a strong point of the importance of social interaction between children, teachers, parents, authorities and other agents outside the school. The project group, however, put farreaching responsibility upon schools regarding their ambition to support passive or isolated children. The holistic ambition involves, for example, organizing peer groups such as 'Circle of Friends'. Activities suggested in this chapter comprise practical advice such as observation protocols, social development plans and detailed action plans for social interaction.

\section{Home-School Collaboration}

The need for collaboration dealt with in chapter four is continued in this chapter. As parents know their child better than anyone else, they have information that is exceedingly important for school staff to become informed of. Many teachers find parent-school collaboration to be an additional workload that takes a lot of time. However, the ETAI study, similarly to results from previous research of parents' involvement in school activities, shows that time invested in such collaboration is well spent. Moreover, it is important to stress that teachers by definition have an advantage over parents by virtue of their professional skills and specialized competence. However, it is also essential to observe that teachers are obliged to use their professional authority in relation to parents.

In order to create a relaxed relationship between school staff and parents, presenting the ideas behind inclusion to parents at a common meeting during the children's first semester in the school is recommended. Parents are then invited to discuss issues of importance for the school, as it should be a place where every child is given ample opportunity of achieving optimal development.

\section{Evaluation and Reflection}

Successful attempts to create inclusive schooling have proven to be dependent upon how well those involved are aware of the outcomes of actions taken. This chapter is about the value and importance of systematic evaluation based on teachers' individual and joint reflection.

Evaluation in education is a relatively new phenomenon. The authors claim that evaluation 'must be democratic and requires the collaboration of the parties involved'. Democratic evaluation in education has been discussed by, among others, Karlsson (2003) and Imsen (2003). In the paper Democratic Evaluation: an arena for dialogue and learning, democratic participatory evaluation is discussed:

First the evaluation should be inclusive and thereby aspire to represent all relevant views, interests, values and stakeholders. Second, there should be sufficient dialogue with relevant groups, ensuring that views are properly and authentically represented. Third, there should be sufficient deliberations to arrive at valid findings. Deliberation might involve ways of protecting evaluators or others from the pressure exerted by powerful stakeholders. (p. 136)

According to Karlsson, it is important to look upon democratic evaluation as a developing social process and as a reaction against a new discourse of evaluation that is built upon principles of New Public Management. This discourse is influenced by elements such as results, effectiveness, professionalism and customer influence.

On the other hand, Imsen claims that democratic evaluation is a risky enterprise, as some people's voices will be heard above others'. Groups of people whose financial, cultural and social capital is large get better access to the public arena, while people who are less well-off are less likely to be listened to. Imsen writes: 
Democratic evaluation will easily follow the law of the jungle, at the cost of the weakest in society.... On the one hand, we have children who possess neither the competence nor the skill that is necessary to express their own interests. It is, on the contrary the schools and teachers' responsibility to protect the students' interests, so that they realize a certain level of knowledge, skill, and attitude to cope with society. (p. 159)

Quite sensibly, the ETAI-group points out possible obstacles to successful evaluation. Accomplished in a deliberate way, evaluation is no doubt one of the key elements in realizing an inclusive schooling.

\section{Support Services}

The overriding objectives of this chapter are to make the different roles of support services known to the reader. The ETAI-findings show that external experts are best used if they adopt a collaborative stance and do not establish themselves in a superior position.

Different intervention models are presented, and it is claimed that in the past, the work carried out by special education teachers and other experts often developed into a kind of institutionalized segregation inside ordinary schools. The road to inclusion began when this was identified as a problem, and questioned.

Direct Intervention Services need to be coordinated with consultation services in order to be successful. This means that different professional groups meet and work together. Direct intervention with regard to pupils involves the most specialized support services belonging to the health sector, while indirect (consultation) services relate to multidisciplinary teams made up of psychologists, social workers and educators.

\section{Staff Development}

The last chapter in the handbook deals with issues concerning staff development and in-service training. Once again, collaboration is emphasized and activities as regards staff development are claimed to be addressed at three levels simultaneously; as a whole school approach, at classroom level as well as work with individual pupils.

Inclusive education revolves around everyone's right to be a full member of the school community and have equal access to education. Therefore, teachers' attitudes need to be focused on achieving this objective.

Enhancing teachers' competence and skills should begin with a thorough mapping of every individual member's level of competence. The authors recommend two elements of staff development to be considered; namely, self-study and context-based approaches. Within this framework, staff can benefit from the support of either colleagues or external consultants.

\section{Included CD}

As a complement to the handbook, the package also contains a 30-minute CD. This professionally produced CD brings snapshots from research in the contributing schools in all four countries. Interviews with teachers as well as sequences where successful classroom practice is illustrated are combined with voices from parents of disabled children as well as parents of non-disabled children attending the same school.

It is evident from theses scenes that if professionals are trained within an inclusive discourse, they also have the skills and knowledge needed to create an inclusive environment in schools. In practice, this means that disabled children are seen as being important resources among both staff members and their peers. Despite the differences between the contributing schools in the project, such positive effects appear to be present in all schools.

\section{Conclusions and Recommendations to Readers}

As was discussed in the introduction to this article, inclusion is a problematic concept, not least because its rhetorical aims are much more discussed than is its substance. The leader of 'Parents of 
Disabled Children Organization' in Norway, Trond Morten Osvold, has described this dilemma by using an illustrative metaphor:

Ten cars with skilled and steady drivers stand on line at the Castle Place in Oslo. When the starting gun goes off, their task is simply to drive to the most beautiful place in the world. With such a vague description, the cars will most probably end up at totally different places, as anything else would be a coincidence.

Osvold continues by claiming that if we want the 10 cars to get to the same place, the road description has to be clear and measurable. In the same way, the description of inclusion has to be the same if all children are to become included:

Schools must have an organization that promotes inclusion

Schools must have an inclusive adaptation of school subjects

Schools must have an inclusive culture

Schools must have an adaptability to social inclusion. (Osvold, 2005, p. 23)

With their handbook the ETAI-group has contributed to describing a road to reaching inclusive practices in schools. By systematically using experiences from practice together with research, this book is an important contribution to the belief that inclusive education is possible. Pathways to Inclusion is therefore warmly recommended for use in schools as well as by educational planners at different levels of the educational system.

\section{Correspondence}

Professor Bengt Persson, Agder University College, PO Box 422, N-4604 Kristiansand S, Norway (bengt.persson@hia.no).

\section{References}

Andreasson, I. (forthcoming) Representations of Pupils with Special Needs in Individual Educational Plans. Doctoral dissertation, Göteborg University.

Bank-Mikkelsen, N.-E. (1964) The Ideological and Legal Basis of the National Service for the Mentally Retarded, in J. Öster \& H. Sletved (Eds). International Copenhagen Congress on the Scientific Study of Mental Retardation. Vol. 1. Copenghagen: Det Berlingske Bogtrykkeri.

Befring, E. \& Tangen, R. (2004) Spesialpedagogikk. Oslo: Cappelen.

Brantlinger, E. (1997) Using Ideology: cases of nonrecognition of the politics of research and practice in special education, Review of Educational Research, 67, pp. 425-459. http:/ / dx.doi.org/10.2307/1170517

Cooper, P. (1996) Are Individual Education Plans a Waste of Paper? British Journal of Special Education, 23(3), pp. 115-119.

Foucault, M. (1974/1993) Discipline and Punish: the birth of the prison. New York: Vintage.

Fuchs, D. \& Fuchs, L.S. (1997) Editorial: lessons from a welfare 'reform', Journal of Special Education, 30(3), pp. 229-231.

Imsen, G. (2003) Democratic Evaluation and Evaluation for Learning: a reply to Ove Karlsson, in I.P. Haug \& T.A. Schwandt (Ed.). Evaluating Educational Reforms: Scandinavian perspectives. Greenwich: Information Age Publishing.

Karlsson, O. (2003) Democratic Evaluation: an arena for dialogue and learning, in I.P. Haug \& T.A. Schwandt (EdS) Evaluating Educational Reforms: Scandinavian perspectives. Greenwich: Information Age Publishing.

Nirje, B. (1992) The Normalization Principle Papers. Uppsala: Centre for Handicap Research, Uppsala University.

Osvold, T.M. (2005) Inkludering - Integrering ute av system. Statped 4/05, p. 23.

Swedish Agency for Education (2003) Kartläggning av åtgärdsprogram och särskilt stöd i grundskolan. Stockholm: Skolverket.

UNESCO (2000) Schools for All: open file on inclusive education. Paris: UNESCO. 